\title{
Optimum Sun Exposure Times for Vitamin D Status Correction in Saudi Arabia
}

\author{
Fahad Alamri ${ }^{1, ~ *}$, Fahad Alshahrani ${ }^{2,4}$, Yousef Al-Saleh ${ }^{4,5}$, Mohammed Yehia Saeedi ${ }^{1}$, \\ Mussa Hussein Almalki ${ }^{3,4}$, Nasser Al-Daghri ${ }^{5}$, Abdulallah Alzahrani ${ }^{5}$, Michael Holick ${ }^{6}$, \\ Ahmed Khair Ibrahim ${ }^{7}$
}

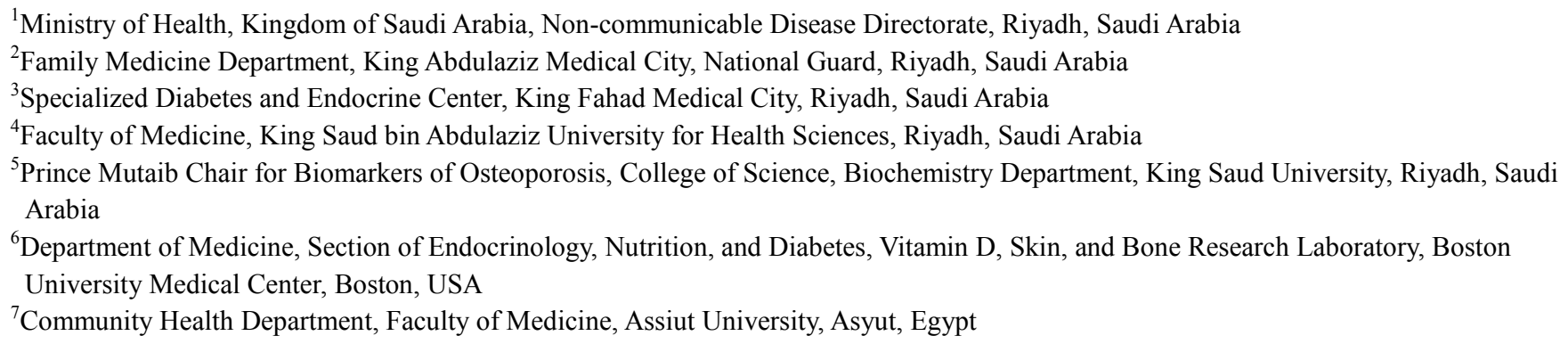

Email address:

fahadamri@yahoo.com (F. Alamri)

\section{To cite this article:}

Fahad Alamri, Fahad Alshahrani, Yousef Al-Saleh, Mohammed Yehia Saeedi, Mussa Hussein Almalki, Nasser Al-Daghri, Abdulallah Alzahrani, Michael Holick, Ahmed Khair Ibrahim. Optimum Sun Exposure Times for Vitamin D Status Correction in Saudi Arabia. European Journal of Preventive Medicine. Vol. 3, No. 5, 2015, pp.147-154. doi: 10.11648/j.ejpm.20150305.14

\begin{abstract}
Vitamin deficiency is considered to be a major public health problem in Saudi Arabia, especially during summer. The major source of vitamin D is sun exposure. In this study, we aimed to determine the optimum time for sun exposure in four different cities (North, South, West and East regions) in the Kingdom of Saudi Arabia. In the current study ampoules containing 7-dehydrocholesterol in ethanol were exposed to sunlight every hour starting from sunrise until sunset in June 2013. Results indicated that the geographical location and the time of the day have a major influence in vitamin $\mathrm{D}$ production. In summer, conversion of pre-vitamin $\mathrm{D}_{3}$ was observed to be elevated between 8.00-9.00 AM to 3:30-4:30 PM, with peak hours between 11:30 AM to 12:30 PM. Moreover in the east region (Dammam), conversion of pre-vitamin $\mathrm{D}_{3}$ showed significant reduction by around $50 \%$. In conclusion, the optimum sun exposure time for vitamin $\mathrm{D}_{3}$ production in the north, south and west regions of Saudi Arabia during summer is from 8:30 AM to 10:30 AM, as well as 2:00 PM to 4:00 PM.Air pollution might be the cause for the decreased conversion of 7-dehydrocholesterol to pre-vitamin $\mathrm{D}_{3}$ in the east region. Conservatively, the optimum time for sun exposure therefore in Dammam city is from 8:30 AM to 10:00 AM, as well as 1:00 PM to 2:30 PM. Knowledge of the optimum sun exposure times during summer can be highly effective in preventing vitamin D deficiency in Saudi Arabia.
\end{abstract}

Keywords: Vitamin D, Sunlight Exposure, Optimum Times, Saudi Arabia

\section{Introduction}

Vitamin D, the sunshine vitamin, plays an essential role in the regulation of calcium and phosphorus absorption as well as optimal bone health (1). However, the effects of vitamin D are not limited to mineral homeostasis and skeletal health maintenance. The presence of vitamin D receptors (VDR) in other tissues and cells in the body suggested that vitamin D physiology extends beyond bone homeostasis. Furthermore, the enzyme responsible for the conversion of $25[\mathrm{OH}] \mathrm{D}$ to its biologically active form [Vitamin $\mathrm{D}(1,25[\mathrm{OH}] \mathrm{D})]$ has been identified in other tissues aside from kidneys $(2,3)$. During the past decade, numerous reports have shown that relatively high proportions of people have low levels of vitamin D (4-9). In sunny areas like Saudi Arabia, vitamin D deficiency is very prevalent in both adults and children (10-13).

The major source of vitamin D is the casual sun exposure and to a lesser extent, dietary intake. Even so, the natural diets that most humans consume contain little amounts of vitamin D, with the exception of wild-caught, oily fish, cod liver oil and 
sun exposed mushrooms (14).

When human skin is exposed to sunlight, the solar UVB ( 290 to $315 \mathrm{~nm}$ ) photons penetrate in to the epidermis. Then they are absorbed by 7-dehydrocholesterol, which is present in the plasma membrane (15-17). The absorption of these energies transforms 7-dehydrocholesterol (7-DHC) into pre-vitamin $\mathrm{D}_{3}$. Because this photochemical process occurs in the plasma membrane, only the cis,cis conformer of pre-vitamin $\mathrm{D}_{3}$ is formed, which, being thermodynamically unstable, is isomerized to vitamin $\mathrm{D}_{3}$ (17). Once formed, vitamin $\mathrm{D}_{3}$ is ejected out of the plasma membrane into the extracellular space where it is drawn into the dermal capillary bed by the vitamin D-binding protein (18). The synthesis of pre-vitamin $\mathrm{D}_{3}$ reaches a plateau of about $10-15 \%$ of the original cutaneous 7-DHC concentrations during a single prolonged sun exposure. At this point, pre-vitamin $D_{3}$ undergoes a process of photo-isomerization resulted into two biologically inactive products (tachysterol and lumisterol), so excessive sunlight exposure will not cause vitamin D toxicity (17).

Known factors that affect cutaneous production of vitamin $\mathrm{D}_{3}$ include latitude, season, time of day, air pollution, cloud cover, glass shielding, melanin content of the skin, use of sun-blockers, age and the extent of clothing covering the body (19). When the sun is low on the horizon, the atmospheric ozone, cloud sand particulate air pollution absorb UVB radiation, limiting the amounts that reach the surface of the Earth. The zenith angle of the sun plays a critical role in

vitamin $\mathrm{D}_{3}$ production. When the zenith angle is more oblique, the path length through the stratospheric ozone layer is increased and hence, fewer UVB photons are able to reach the earth's surface. Therefore, cutaneous vitamin $\mathrm{D}_{3}$ production is effectively absent early and late in the day and for the entire day during several winter time months at latitudes $>35^{\circ}$ (20-22).

The present study aimed to determine the optimum time for sun exposure during summer by evaluating pre-vitamin $D_{3}$ production in four different regions of Saudi Arabia [Arar City $\left(30^{\circ} \mathrm{N}\right)$ located at north area, Abha City $\left(18^{\circ} \mathrm{N}\right)$ located at south area, Makkah City $\left(21^{\circ} \mathrm{N}\right)$ located at western area and Dammam City $\left(26^{\circ} \mathrm{N}\right)$ located at eastern province].

\section{Methodsand Materials}

In the current study 7-dehydrocholesterol in ethanol was sealed under Argon in borosilicate ampoules, placed outside in direct sunlight on a cloudless day of June 2013 in each of the four regions after sunlight exposure for one hour intervals beginning from 6.00 AM to 6.00 PM. The samples were stored in the dark and evaluated by high-performance liquid chromatography (HPLC) for the conversion of 7-dehydrocholesterol to pre-vitamin $\mathrm{D}_{3}$ and its photoproducts (tachysterol and lumisterol).

\section{Results}

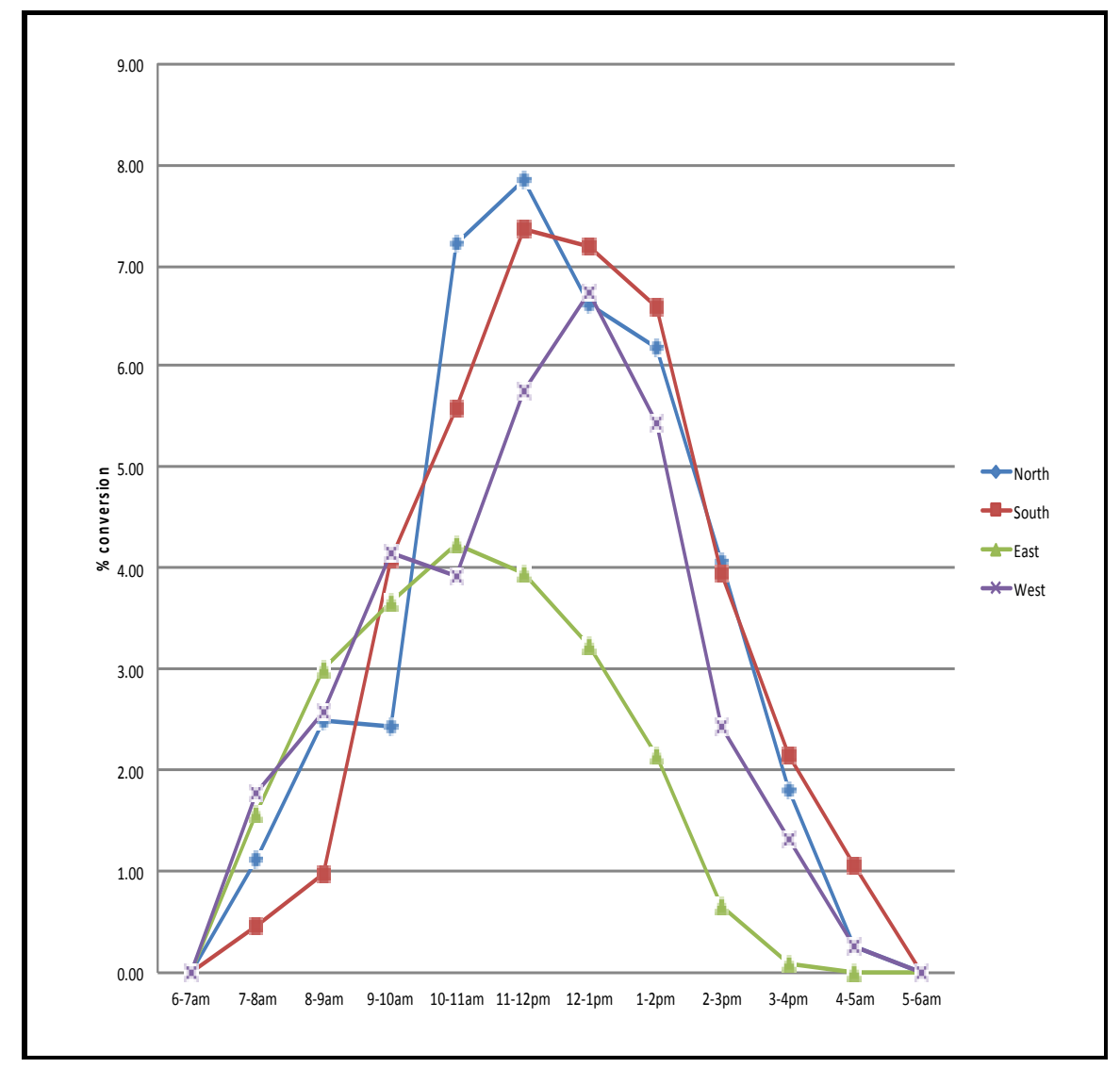

Fig. 1. Synthesis of pre-vitamin D3 overtime in the four different regions in the kingdom of Saudi Arabia. 
The conversion of 7-dehydrocholesterol to pre-vitamin $\mathrm{D}_{3}$ in the ampules is the most sensitive indicator for the cutaneous production of vitamin D from sun exposure. Using this method, we observed that although the sun was shining brightly beginning at around 6.00 AM in June, pre-vitamin $\mathrm{D}_{3}$ were detected in the ampules exposed to sunlight between $8.00-9.00 \mathrm{AM}$ (fig.1). No significant pre-vitamin $\mathrm{D}_{3}$ production was detected before $9.00 \mathrm{AM}$ in Abha (fig.2). However, it was detected in other cities earlier at around 8.00 AM. Succeeding hours showed gradual pre-vitamin $\mathrm{D}_{3}$ production increased and reached its maximum at around 11:30 AM in Dammam (fig.3) and around 12:30 PM in other cities. Pre-vitamin $\mathrm{D}_{3}$ production gradually declined and none were observed in ampoules exposed to sunlight after 3:30 PM in Dammam (fig.3), 4.00 PM in Arar \& Makkah (fig.4\&5) and around 4:30 PM in Abha (fig.2).

Tachysterol and lumisterol were detected in the ampoules exposed to sunlight between 9.00-10.00 AM and 3.00-4.00 PM, demonstrating that enough sunlight was available to convert pre-vitamin $\mathrm{D}_{3}$ to these two photoproducts and thus beginning to establish a photo-equilibrium.

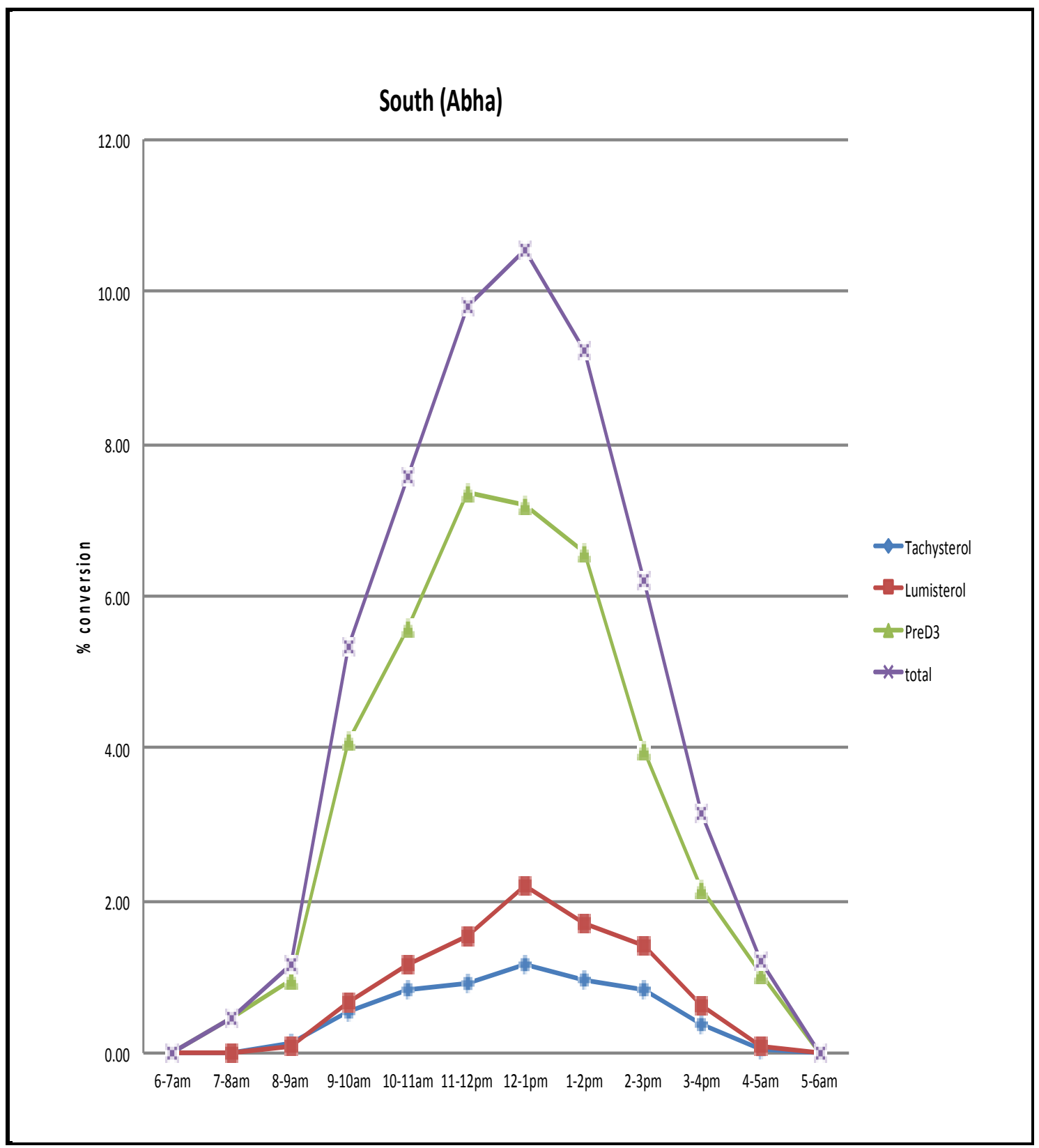

Fig. 2. Conversion of 7-dehydrocholesterol (7-DHC) to pre-vitamin D3 overtime in June, 2013 in Abha, Saudi Arabia 


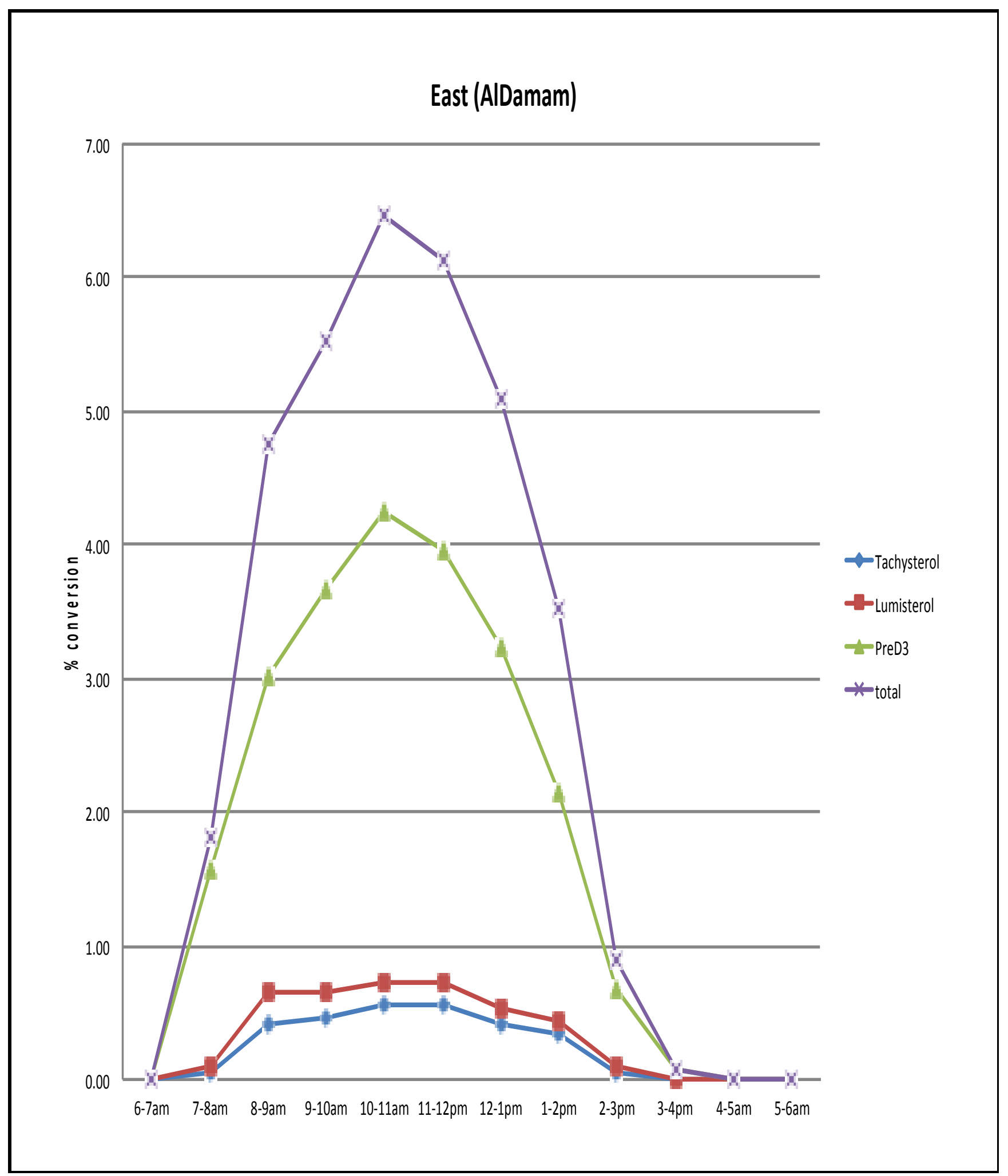

Fig. 3. Conversion of 7-dehydrocholesterol (7-DHC) to pre-vitamin D3 overtime on June,2013 in Dammam, Saudi Arabia 


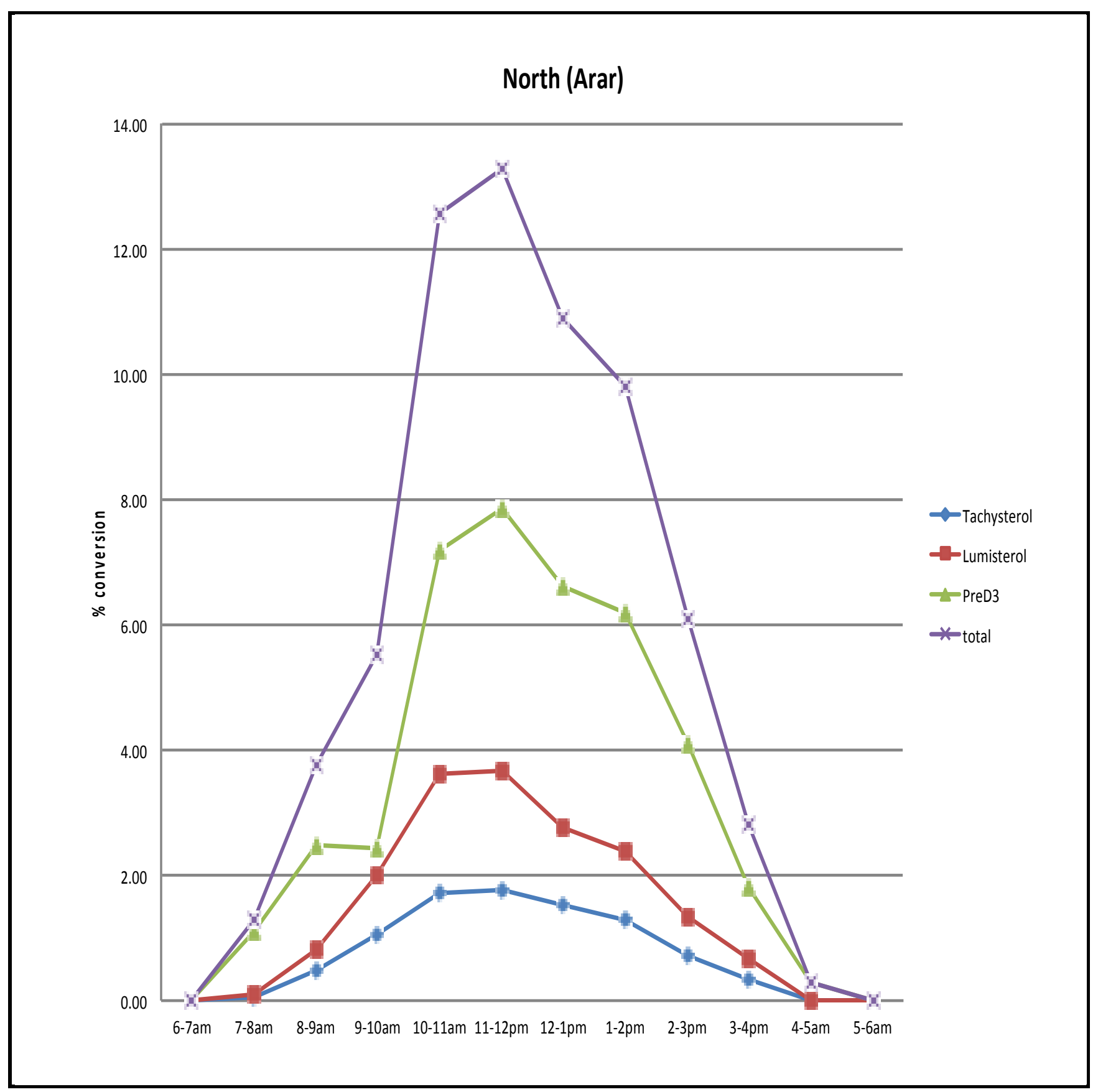

Fig. 4. Conversion of 7-dehydrocholesterol (7-DHC) to pre-vitamin D3 overtime on June, 2013 in Arar, Saudi Arabia 


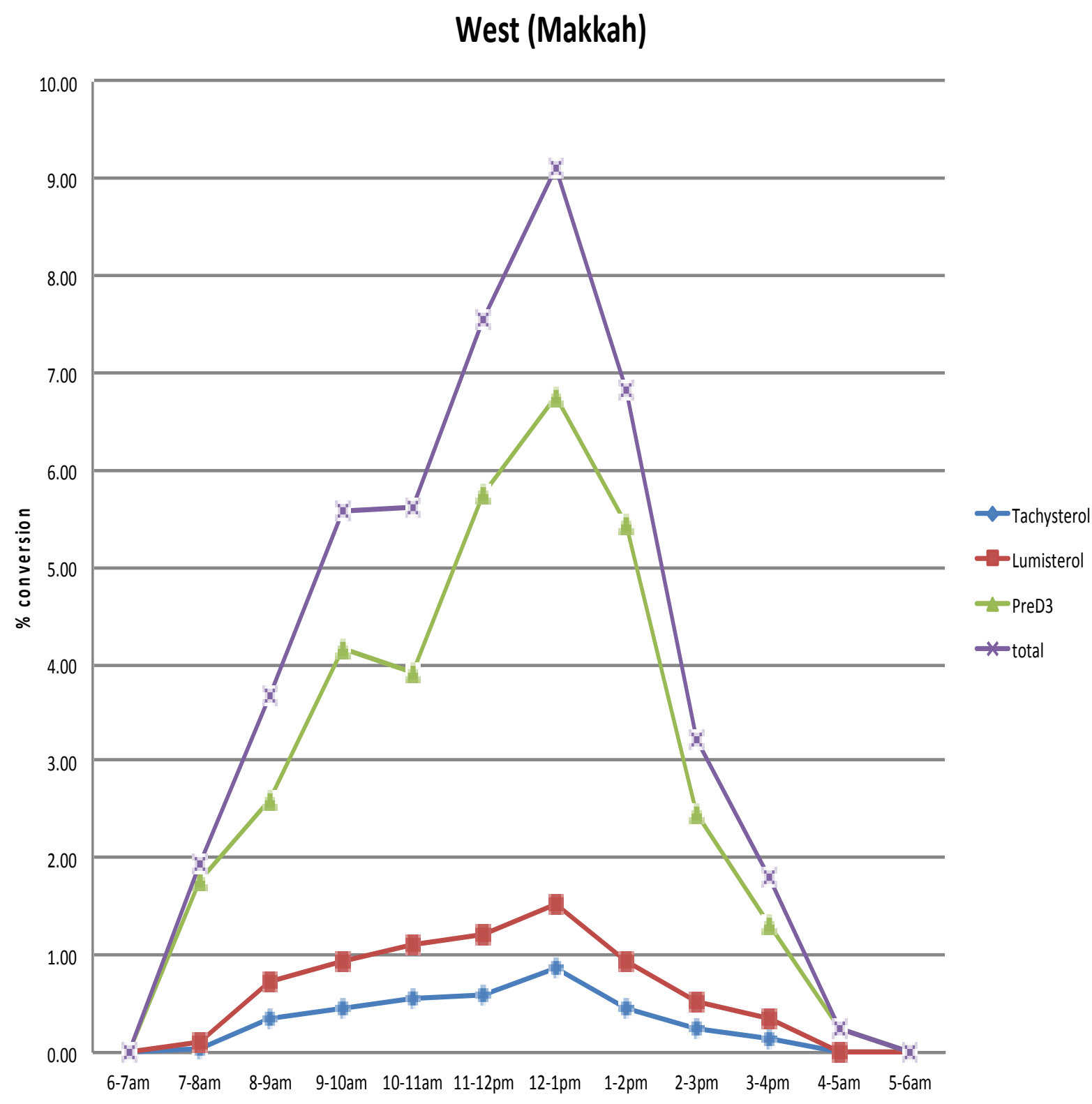

Fig. 5. Conversion of 7-dehydrocholesterol (7-DHC) to pre-vitamin D3 overtime in June, 2013 on a sunny day in Makkah, Saudi Arabia

\section{Discussion}

The best way to increase vitamin D levels is to expose the skin to the sun especially in sunny countries like Saudi Arabia. This has never been known to cause toxicity because of self-regulatory factors in the skin. However, vitamin D deficiency is an all-year-round problem in the country, and this worsen during the summer as people avoid the sun because of extreme heat (23).

Several factors may affect vitamin D production in the skin such as amount of sun exposure, time of the day, season, latitude, and skin color. Our results demonstrated that the time of the day has a major influence on cutaneous vitamin D production.

In the current study, summer conversion of pre-vitamin $\mathrm{D}_{3}$ was observed to start around 8:00 AM in Makkah, Arar and Dammam and around 9.00 AM in Abha. Peak conversion was around 11:30 AM in Dammam and 12:30 PM in other cities before declining onwards. These results were longer (9:00 AM- 3:00 PM) with peak hours between 10:00 AM and 12:00 noon in comparison with a previous study carried out in Riyadh (latitude $24^{0} \mathrm{~N}$ ), during month of July, 2012 (24). Likewise, Holick et al, reported that pre-vitamin $\mathrm{D}_{3}$ production in Boston (latitude $42^{0} \mathrm{~N}$ ) was more between hours of 10:00 AM- 4:00 PM during June, 2007 (25). When the sun is low on the horizon, the atmospheric ozone, clouds and 
particulate air pollution absorb UVB radiation, limiting the amount that reaches the Earth's surface. The zenith angle of the sun plays a critical role in vitamin $\mathrm{D}_{3}$ production (26). When the zenith angle is more oblique, the path length through the stratospheric ozone layer is increased and hence, fewer UVB photons are able to reach the earth's surface (26). Therefore, cutaneous vitamin $\mathrm{D}_{3}$ production is effectively absent early and late in the day and for the entire day during several winter time months at latitudes $>35^{\circ}(20-22)$. Dammam city, which is located in the eastern province, is considered an industrial city. Hence, air pollution could explain the significant reduction of pre-vitamin $\mathrm{D}_{3}$ production by almost $50 \%$ than the other cities.

Moreover, the sun's path gradually drifts northward and by June, the sun rises considerably north due east and sets considerably north due west. This means that the sun's rays strike the ground more directly at higher latitudes, and explains the relatively higher amount of pre-vitamin $\mathrm{D}_{3}$ in Arar (latitude $30^{\circ} \mathrm{N}$ ) (fig.4) compared with Abha (latitude $\left.18^{0} \mathrm{~N}\right)$.

The maximum UVB time is believed to be responsible for both sunburn and skin cancer, so it's equally important to determine these time frames in each city. During the summer months in Riyadh, the maximum UVB time was recorded between 10:30 AM- 2:00 PM (27). Taking this into account, the optimum time for sun exposure therefore in north, south and west provinces is from 8:30 AM- 10:30 AM, as well as after 2:00 PM- 4:00 PM. Consequently, the suggested optimum time for sun exposure in Dammam city is from 8:30 AM- 10:00 AM, as well as after 1:00 PM- 2:30 PM.

The amount of UVB irradiation required for vitamin D sufficiency can be calculated from the amount of vitamin D produced from one minimal erythemal dose (MED). The MED can be defined as the amount of time needed to cause skin to turn pink. Several factors have been identified to affect the MED i.e. geographical location, skin pigmentation, percent of body fat, and age (28).

The production of vitamin $\mathrm{D}_{3}$ from oral supplementation versus sun exposure has been evaluated in several studies. The whole body exposure of mid-day sun in summer for 10-15 minutes was comparable to taking 15,000 IU of vitamin $D_{3}$ orally (29). Based on this, exposure of hands, face and arms (around 15\% of body surface area) should produce about 1000 IU of vitamin $\mathrm{D}_{3}$. It has been suggested that the concentration of the pre-vitamin $\mathrm{D}_{3}$ in the skin of Caucasians reaches equilibrium within 20 minutes of UVB exposure (17), with any excess 7-DHC being converted to inactive metabolites. Therefore, UVB exposure beyond the MED does not increase vitamin $D$ production further that explains why it is impossible to get toxicity from UVB radiation.

Our study has encountered few limitations. The study was carried out during summer season only. Further studies are needed to determine the effect of change in the season throughout the year on skin production of pre-vitamin D3. In addition, the study was conducted in four cities from different regions accordingly; optimum sun exposure times might not be the same from other geographical regions in the country secondary to differences in weather, air pollution status and altitude.

In summary, the optimum sun exposure times during summer in the four cities of Saudi Arabia have been identified based on pre-vitamin $\mathrm{D}_{3}$ conversion. A similar study is suggested during winter times. These suggested time-schedules for sun exposure during summer, once implemented by the general community, may effectively help battle the vitamin D deficiency pandemic in the country.

\section{References}

[1] DeLuca H. Overview of general physiologic features and functions of vitamin D. The American journal of clinical nutrition. 2004;80(6 ):1689S-96S

[2] Mawer E, Hayes M, Heys S, Davies M, White A, Stewart M, et al. Constitutive synthesis of 1,25-dihydroxyvitamin D3 by a human small cell lung cancer cell line. J Clin Endocrinol Metab. 1994;79(2):554-60.

[3] Schwartz G, Whitlatch L, Chen T, Lokeshwar B, Holick M. Human prostate cells synthesize 1,25-dihydroxyvitamin D3 from 25-hydroxyvitamin D3. Cancer Epidemiol Biomarkers Prev. 1998;7(5):391-5.

[4] Bener A, Al-Ali M, Hoffmann G. High prevalence of vitamin D deficiency in young children in a highly sunny humid country: a global health problem. Minerva Pediatr. 2009;61(1):15-22.

[5] Bodnar L, Simhan H, Powers R, Frank M, Cooperstein E, Roberts J. High prevalence of vitamin D insufficiency in black and white pregnant women residing in the northern United States and their neonates. J Nutr. 2007;137(2):447-52.

[6] Chapuy M, Preziosi P, Maamer M, Arnaud S, Galan P, Hercberg S, et al. Prevalence of Vitamin D Insufficiency in an Adult Normal Population Osteoporos Int 1997;7(1):439-43.

[7] Gordon C, DePeter K, Feldman H, Grace E, Emans J. Prevalence of Vitamin D Deficiency Among Healthy Adolescents. Arch Pediatr Adolesc Med. 2008;158(6):531-7.

[8] Roth D, Martz P, Yeo R, Prosser C, Bell M, Jones A. Are national vitamin $\mathrm{D}$ guidelines sufficient to maintain adequate blood levels in children? Can J Public Health. 2005;96(6):443-9.

[9] Rucker D, Allan J, Fick G, Hanley D. Vitamin D insufficiency in a population of healthy western Canadians. CMAJ. 2002;166(12):1517-24.

[10] Al-Daghri N, Al-Attas O, Al-Okail M, Alkharfy K, Al-Yousef M, Nadhrah H, et al. Severe hypovitaminosis D is widespread and more common in non-diabetics than diabetics in Saudi adults. Saudi Med J. 2010;31(7):775-80.

[11] Al-Daghri N, Al-Attas O, Alokail M, Alkharfy K, Yousef M, Nadhrah H, et al. Hypovitaminosis D and Cardiometabolic Risk Factors among Non-obese Youth. Cent Eur J Med. 2010;5(6):752-7.

[12] Ardawi M, Sibiany A, Bakhsh T, Qari M, Maimani A. High prevalence of vitamin D deficiency among healthy Saudi Arabian men: relationship to bone mineral density, parathyroid hormone, bone turnover markers, and lifestyle factors. Osteoporos Int. 2012;23(2):675-86. 
[13] Elsammak M, Al-Wosaibi A, Al-Howeish A, Alsaeed J. Vitamin d deficiency in Saudi Arabs. Horm Metab Res. 2010;42(5):364-8.

[14] Cannell J, Hollis B, Zasloff M, Heaney R. Diagnosis and treatment of vitamin D deficiency. Expert Opin Pharmacother. 2008;9(1):1-12.

[15] Holick M. Vitamin D: A millenium perspective. Journal of cellular biochemistry. 2003;88(2):296-307.

[16] Holick M, MacLaughlin J, Clark M, Holick S, Potts J, Anderson R, et al. Photosynthesis of previtamin D3 in human skin and the physiologic consequences. Science. 1980;210(4466):203-5.

[17] Holick M, Tian X, Allen M. Evolutionary importance for the membrane enhancement of the production of vitamin D3 in the skin of poikilothermic animals. Proc Natl Acad Sci U S A. 1995;92(8):3124-6.

[18] Whyte M, Haddad J, Walters D, Stamp T. Vitamin D bioavailability: serum 25 -hydroxyvitamin $\mathrm{D}$ levels in man after oral, subcutaneous, intramuscular, and intravenous vitamin D administration. J Clin Endocrinol Metab. 1979;48(6):906-11.

[19] Holick M. Photosynthesis of vitamin D in the skin: effect of environmental and life-style variables. Fed Proc. 1987;46(5):1876-82.

[20] Chen T. Photobiology of Vitamin D. In: Holick M, editor. Vitamin D. Nutrition and Health. 1: Humana Press; 2010. p. 35-60.

[21] Pener B. Spectral intensity of natural UVR and its dependence on various parameters. In: Urbach F, editor. The Biologic effects of ultraviolet radiation,: With emphasis on the skin Oxford and New York: Pergamon Press; 1969. p. 351-8.
[22] Webb A, Kline L, Holick M. Influence of season and latitude on the cutaneous synthesis of vitamin D3: exposure to winter sunlight in Boston and Edmonton will not promote vitamin D3 synthesis in human skin. J Clin Endocrinol Metab. 1988;67(2):373-8.

[23] Al-Daghri N, Al-Attas O, Alokail M, Alkharfy K, El-Kholie E, Yousef $\mathrm{M}$, et al. Increased vitamin $\mathrm{D}$ supplementation recommended during summer season in the gulf region: a counterintuitive seasonal effect in vitamin D levels in adult, overweight and obese Middle Eastern residents. Clinical Endocrinology. 2012;76(3):346-50.

[24] Alshahrani F, Almalki M, Aljohani N, Alzahrani A, Alsaleh Y, Holick M. Vitamin D: Light side and best time of sunshine in Riyadh, Saudi Arabia. Dermatoendocrinol. 2013;5(1):177-80.

[25] Holick M, Chen T, Lu Z, Sauter E. Vitamin D and skin physiology: a D-lightful story. J Bone Miner Res. 2007;22(7):V28-33.

[26] Holick M. Shedding new light on the role of the sunshine vitamin D for skin health: the lncRNA-skin cancer connection. Experimental Dermatology. 2014;23(6):391-2.

[27] Hannan M, Paul M, Amer M, Al-Watban F. Study of ultraviolet radiation and genotoxic effects of natural sunlight in relation to skin cancer in Saudi Arabia. Cancer Res. 1984;44(5):2192-7.

[28] Holick M. Sunlight and vitamin D for bone health and prevention of autoimmune diseases, cancers, and cardiovascular disease. Am J Clin Nutr. 2004;80(6):1678s-88s.

[29] Holick M. Vitamin D: the underappreciated D-lightful hormone that is important for skeletal and cellular health. Current Opinion in Endocrinology Diabetes and Obesity. 2002;9(1):87-98. 